\title{
Asteraceae da Ecorregião Raso da Catarina, Bahia, Brasil
}

\author{
Asteraceae from the Ecoregion Raso da Catarina, Bahia, Brazil
}

\author{
Vivian Oliveira Amorim ${ }^{1}$ \& Hortensia Pousada Bautista ${ }^{1,2}$
}

\begin{abstract}
Resumo
No Brasil são referidas para Asteraceae 2.065 espécies distribuídas em 278 gêneros, sendo a terceira maior família das angiospermas no país. O Raso da Catarina é uma das ecorregiões do domínio Caatinga, caracterizada pelo clima quente e seco e uma caatinga arbustiva densa. O objetivo do presente estudo foi realizar o levantamento florístico de Asteraceae da Ecorregião Raso da Catarina, discutir o ambiente de ocorrência e apresentar uma chave de identificação para as espécies. Foram realizadas 17 expedições mensais a campo no período de abril/2012 a agosto/2013 e análise das coleções dos herbários: ALCB, BAH, CEPEC, HRB, HUEFS e HUNEB. A família foi representada por 52 espécies, 41 gêneros e 14 tribos. Em ordem de riqueza, representam a diversidade local de Asteraceae as tribos: Vernonieae (11 spp.), Heliantheae (10 spp.), Eupatorieae (9 spp.), Tageteae (5 spp.), Astereae (4 spp.), Senecioneae (3 spp.), Gnaphalieae e Millerieae (2 spp.) cada, Cichorieae, Coriopsideae, Gochnatieae, Inuleae, Nassauvieae e Neurolaene (1 spp.) cada. Os gêneros mais representativos foram Lepidaploa, Pectis e Trichogonia, com três espécies cada. Sete espécies são endêmicas de Caatinga. O hábito herbáceo é predominante e as espécies encontradas ocorrem principalmente na caatinga aberta.
\end{abstract}

Palavras-chave: caatinga, Compositae, florística, semiarido.

\begin{abstract}
The Asteraceae represent the third largest family of flowering plants in Brazil comprising 2.070 species distributed in 280 genera. Raso da Catarina is an ecoregion in the Caatinga domain characterized by warm and dry climate and a schruby xeric vegetation. The current study aims (1) to survey the Asteraceae flora in Raso da Catarina; (2) to discuss environmental occurrence and (3) to provide an identification key. Samples were collected during 17 monthly expeditions from April/2012 to August/2013 and analyzed in the following herbaria collections: ALCB, BAH, CEPEC, HRB, HUEFS and HUNEB. The family was represented in the region by 52 species, 42 genera and 14 tribes. In order of richness, the local diversity of Asteraceae is presented by the tribes: Vernonieae (11 spp.), Heliantheae (10 spp.), Eupatorieae (9 spp.), Tageteae (5 spp.), Astereae (4 spp.), Senecioneae (3 spp.), Gnaphalieae, and Millerieae (2 spp.), Cichorieae, Coriopsideae, Gochnatieae, Inuleae, Nassauvieae e Neurolaene (1 spp.) each. The most representative genera were Lepidaploa, Pectis and Trichogonia, with three species each. Seven species are endemic to Caatinga. The herbaceous habit is predominant among the species, which occurs mainly in less schruby open caatinga.
\end{abstract}

Key words: caatinga, Compositae, floristic, semiarid.

\section{Introdução}

Asteraceae destaca-se mundialmente pela diversidade e importância econômica, ornamental e medicinal, sendo comumente encontrada em áreas abertas e menos frequente em áreas florestais. A diversidade da família está estimada entre 24.000-30.000 espécies distribuídas em
1.600-1.700 gêneros, 12 subfamílias e 43 tribos (Funk et al. 2009). No Brasil são referidas para Asteraceae 2.070 espécies distribuídas em 280 gêneros, representando a terceira maior família das angiospermas no país (BFG 2015). Na Caatinga está entre as 12 famílias mais ricas com 290 espécies em 109 gêneros (Queiroz et al. 2006; BFG 2015).

\footnotetext{
${ }^{1}$ Universidade do Estado da Bahia, Depto. Educação, Programa de Pós-graduação em Biodiversidade Vegetal, R. do Gangorra 503, Centro, 48608-240, Paulo Afonso, BA, Brasil.vy_2209@hotmail.com

${ }^{2}$ Universidade do Estado da Bahia, Depto. Ciências da Vida, R. Silveira Martins 2555, Cabula, 41150-000, Salvador, BA, Brasil. hortbautista@gmail.com
} 
Dentre os trabalhos que estudaram Asteraceae na Caatinga destaca-se Agra \& Barbosa (1996) com uma lista anotada do Estado da Paraíba, Giulietti et al. (2002) com a flora da Caatinga, Pereira \& Melo (2009) com a listagem da flora de Mirandiba em Pernambuco e Siqueira-Filho (2012) com a flora das Caatingas do Rio São Francisco.

Estudos realizados na Caatinga reconhecem uma diversidade de fatores edafoclimáticos e diferentes formas de relevo que revelam um mosaico de paisagens, com vales úmidos, chapadas sedimentares e amplas superfícies pediplanadas que geram uma elevada diversidade florística nessas áreas (Sampaio et al. 2002). Atualmente essa diversidade de fitofisionomias e composições florísticas são reconhecidas como ecorregiões.
O Raso da Catarina é uma das oito ecorregiões do domínio Caatinga delimitada pela bacia sedimentar Tucano-Jatobá, localizada na porção Centro-Leste do domínio, caracterizada por um clima marcadamente sazonal que chega a ser um dos núcleos mais secos com estiagem de dez a onze meses ao ano, a vegetação é do tipo caatinga predominantemente arbustiva e muito densa, menos espinhosa do que a caatinga sobre solos cristalinos (Velloso et al. 2002).

Diante do exposto, este trabalho tem por objetivo realizar o levantamento florístico da família Asteraceae da Ecorregião Raso da Catarina, bem como evidenciar o ambiente de ocorrência e prováveis endemismos da flora de Asteraceae da Caatinga.

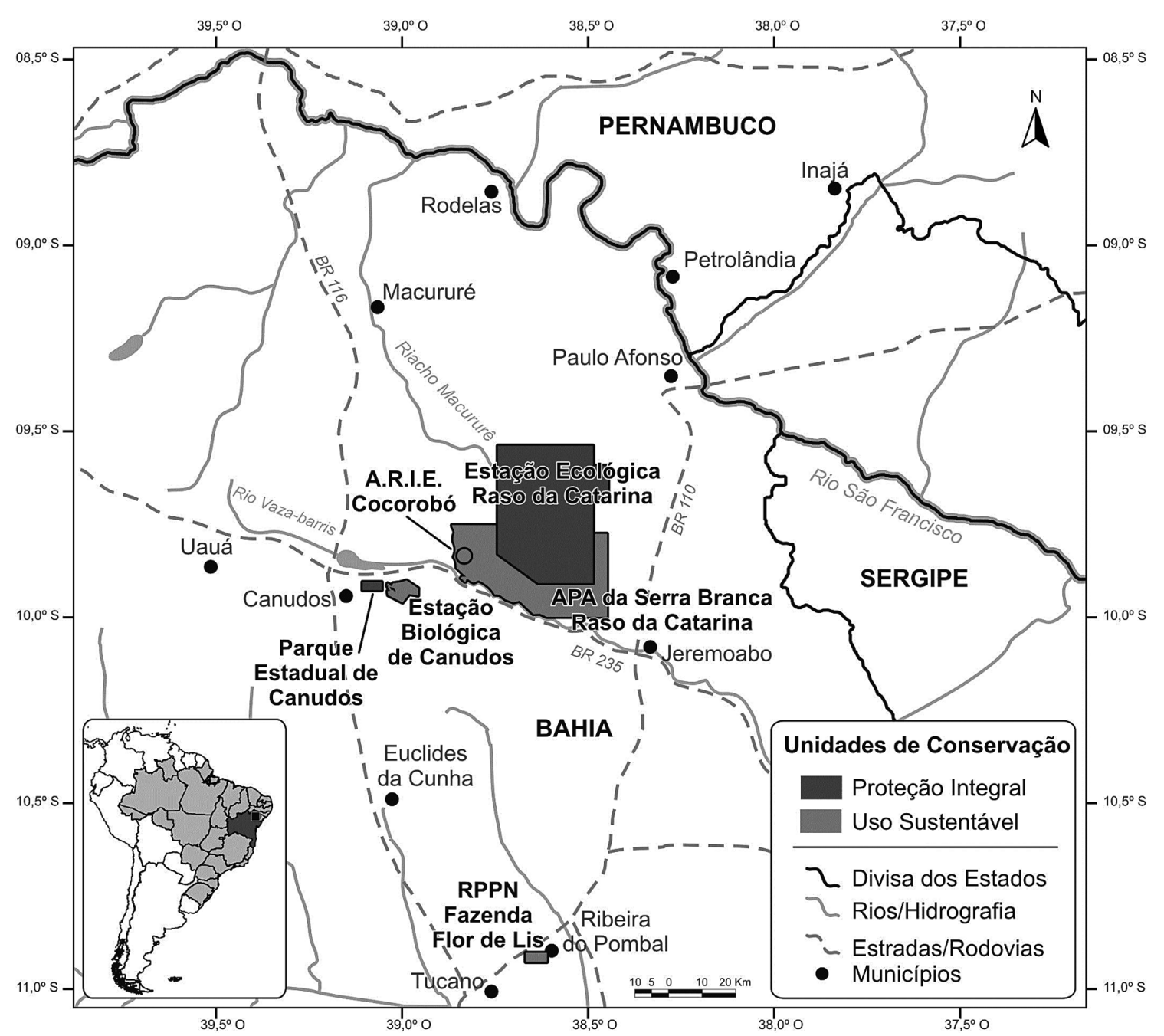

Figura 1 - Localização das unidades de conservação da Ecorregião Raso da Catarina no estado da Bahia. Figure 1 - Location of conservation units in the Ecoregion Raso da Catarina of Bahia state. 


\section{Material e Métodos}

A Ecorregião Raso da Catarina compreende porções dos estados de Pernambuco e Bahia, circunscrevendo uma faixa estreita e alongada no sentido Norte-Sul na porção Centro-Leste do bioma. Possui $30.800 \mathrm{~km}^{2}$ estabelecidos pelos limites naturais geomorfológicos da bacia sedimentar Tucano-Jatobá, possui solos profundos, excessivamente drenados, ácidos e de fertilidade muita baixa (Velloso et al. 2002). A porção territorial correspondente à área de estudo refere-se à parte Sul (Bahia) da Ecorregião Raso da Catarina e abrange parte dos municípios de Canudos, Cícero Dantas, Chorrochó, Euclides da Cunha, Glória, Jeremoabo, Macururé, Paulo Afonso, Ribeira do Pombal, Rodelas, Santa Brígida e Uauá. As excursões a campo ocorreram principalmente nas cinco unidades de conservação (Fig. 1): APA Serra Branca; Estação Biológica de Canudos; Estação Ecológica Raso da Catarina; Parque Estadual de Canudos e RPPN Fazenda Flor de Lis.

Foram realizadas 17 expedições a campo, com duração de cinco dias cada, no período de abril de 2012 a agosto de 2013, incluindo cerca de três áreas por expedição, seguindo a metodologia de campo proposta por Filgueiras et al. (1994), coletando indivíduos em estágio reprodutivo ao longo do trajeto. Além disso, foram analisadas as exsicatas depositadas nos herbários ALCB, BAH, CEPEC, HRB, HUEFS e HUNEB (acrônimos conforme Thiers, continuamente atualizado). Todos os espécimes foram georreferenciados e fotografados. O material coletado foi herborizado segundo as técnicas usuais (Mori et al. 1989) e incorporados ao acervo do herbário da Universidade do Estado da Bahia (HUNEB - Coleção Paulo Afonso). Os capítulos foram fixados em álcool a 70\% e etiquetados com o mesmo número de coleta, para posteriores análises morfológicas.

As identificações foram realizadas por meio de análise de caracteres vegetativos e reprodutivos, utilizando literaturas especializadas (e.g., Baker 1873, 1876, 1882, 1884; Bautista 1987; King \& Robinson 1987; Barroso et al. 1991; Hind 1995; Santos 2001; Anderberg et al. 2007; Roque et al. 2012), protólogos, comparação com material herborizado e imagens de espécimes tipo depositados nos herbários disponíveis online.

\section{Resultados e Discussão}

Para Asteraceae na Ecorregião Raso da Catarina foram catalogadas 52 espécies, 41 gêneros e 14 tribos (Tab. 1). O hábito herbáceo foi predominante entre as espécies catalogadas, o mesmo resultado foi encontrado por Pereira \& Melo (2009) na flora de Mirandiba-PE, contudo, esperava-se a predominância do hábito subarbustivo devido principalmente ao longo período de estiagem e a efemeridade das ervas nesse período.

Os gêneros mais representativos foram Lepidaploa (Cass.) Cass., Pectis L. e Trichogonia Gardner, com três espécies cada. As tribos que apresentaram maior diversidade na área foram Vernonieae (11 spp., 21\%) seguida por Heliantheae (10 spp., 19\%) e Eupatorieae (9 spp., 18\%). Estas tribos são também as mais representativas no Brasil e o padrão exibido é encontrado em outros trabalhos em campo rupestre e cerrado na região Sudeste (Nakajima \& Semir 2001; Almeida et al. 2005). Em áreas de floresta na região Sul foi encontrado outro padrão, Astereae e Eupatorieae, como as mais representativas (Ritter \& Baptista 2005; Beretta et al. 2008). Do total, 11 (21\%) das espécies possuem distribuição geográfica exclusiva ao Nordeste do Brasil e, entre essas, sete espécies: Aspilia bonplandiana (Gardner) S.F. Blake, Chresta martii (DC.) H. Rob., Enydra radicans (Willd.) Lack, Mattfeldanthus andrade-limae (G.M. Barroso) Dematt., Stilpnopappus pratensis Mart. ex DC., Trichogonia heringeri R.M. King \& H. Rob. e Wedelia hookeriana Gardner, são restritas à Caatinga, sendo $W$. hookeriana uma nova ocorrência para Bahia.

Ainda são escassos levantamentos florísticos em áreas de caatinga, sobretudo com espécies de Asteraceae. Em alguns poucos checklists existentes para a caatinga, a família é representada geralmente entre 3 e 10 espécies (Rodal et al. 1998; Barbosa et al. 2000; Lemos \& Merguro 2010). Os estudos mais representativos de Asteraceae foram a Flora de Mirandiba de Pereira \& Melo (2009) que registrou 17 espécies, das quais 15 foram encontradas na Ecorregião Raso da Catarina. $\mathrm{Na}$ lista das espécies ocorrentes na Caatinga do semiárido nordestino brasileiro (Queiroz et al. 2006), na qual foram registradas 35 espécies, destas, 16 foram catalogadas neste estudo. Com base na literatura apresentada, o presente trabalho representa a maior lista de Asteraceae em estudos de flora local em caatinga.

Na caatinga, em poucos dias se inicia e finaliza o período de floração de algumas espécies, outras, mesmo durante o período de estiagem podem ser encontradas com flores como ocorreu na área com Conocliniopsis prasiifolia (DC.) R.M. King \& H. 
Tabela 1 - Espécies de Asteraceae da Ecorregião Raso da Catarina, Bahia, Brasil, listadas pelas tribos, conforme Funk et al. (2009). Hábito: Sub = subarbustivo; Erv = erva; Lia = liana; Arb = arbusto. Os vouchers são dos coletores: V.O. Amorim (V.O); V.S. Almeida (V.S); T.M.S. Melo (T.M); A.S. Conceição (A.S); D.D. Vieira (D.D); M.V. Romão (M.V); F.H.M. Silva (F.H); L.P. Queiroz (L.P); E.B. Miranda (E.B); D.C. Silva (D.C); H.P. Bautista (H.P); G.O. Matos (G.O); R.M. King (R.M).

Table 1 - Species of Asteraceae of the Ecoregion Raso da Catarina, Bahia, Brazil, listed by tribes, according to Funk et al. (2009). Habits: Sub= Subshrub; Her = herb; Vin = Vine; Shr = Shrub. The voucher are of the collectors: V.O. Amorim (V.O); V.S. Almeida (V.S); T.M.S. Melo (T.M); A.S. Conceição (A.S); D.D. Vieira (D.D); M.V. Romão (M.V); F.H.M. Silva (F.H); L.P. Queiroz (L.P); E.B. Miranda (E.B); D.C. Silva (D.C); H.P. Bautista (H.P); G.O. Matos (G.O); R.M. King (R.M).

\begin{tabular}{|c|c|c|}
\hline Tribo / espécie & Hábito & Voucher \\
\hline \multicolumn{3}{|l|}{ Astereae (3 gêneros, 4 espécies) } \\
\hline Baccharis cinerea DC. & Sub & V.O 67 \\
\hline Baccharis glutinosa Pers. & Herb & G.O 73 \\
\hline Conyza bonariensis (L.) Cronquist & Herb & V.O 279 \\
\hline Egletes viscosa (L.) Less. & Herb & L.P 762 \\
\hline \multicolumn{3}{|l|}{ Cichorieae (1 gênero, 1 espécie) } \\
\hline Sonchus oleraceus L. & Herb & V.O 291 \\
\hline \multicolumn{3}{|l|}{ Coreopsideae (1 gênero, 1 espécie) } \\
\hline Bidens pilosa $\mathrm{L}$. & Herb & V.O 120 \\
\hline \multicolumn{3}{|l|}{ Eupatorieae (6 gêneros, 9 espécies) } \\
\hline Ageratum conyzoides L. subsp. conyzoides & Herb & D.D 111 \\
\hline Conocliniopsis prasiifolia (DC.) R.M. King \& H. Rob. & Sub & V.O 126 \\
\hline Koanophyllon conglobatum (DC.) R.M. King \& H. Rob. & Sub & V.O 156 \\
\hline Mikania cordifolia (L.f.) Willd. & Lia & V.O 232 \\
\hline Mikania obovata DC. & Lia & L.P 337 \\
\hline Platypodanthera melissifolia (DC.) R.M. King \& H. Rob. subsp. melissifolia & Herb & A.S 200 \\
\hline Trichogonia campestris Gardner & Sub & A.S 1661 \\
\hline Trichogonia heringeri R.M. King \& H. Rob. & Sub & V.O 239 \\
\hline Trichogonia salviifolia Gardner & Sub & D.D 83 \\
\hline \multicolumn{3}{|l|}{ Gnaphalieae (2 gêneros, 2 espécies) } \\
\hline Achyrocline satureioides (Lam.) DC. & Sub & T.M 73 \\
\hline Gamochaeta americana (Mill.) Wedd. & Herb & V.O 152 \\
\hline \multicolumn{3}{|l|}{ Gochnatieae (1 gênero, 1 espécie) } \\
\hline Moquiniastrum oligocephalum (Gardner) G. Sancho & Arb & V.O 135 \\
\hline \multicolumn{3}{|l|}{ Heliantheae ( 9 gêneros, 10 espécies) } \\
\hline Acmella uliginosa (Sw.) Cass. & Herb & D.D 420 \\
\hline Aspilia bonplandiana (Gardner) S.F. Blake & Sub & L.P 7239 \\
\hline Aspilia martii Baker & Herb & V.O 134 \\
\hline Blainvillea acmella (L.) Philipson & Herb & V.O 127 \\
\hline Delilia biflora (L.) Kuntze & Herb & V.O 117 \\
\hline Eclipta prostrata (L.) L. & Herb & V.O 130 \\
\hline Melanthera latifolia (Gardner) Cabrera & Sub & V.O 132 \\
\hline
\end{tabular}




\begin{tabular}{|c|c|c|}
\hline Tribo / espécie & Hábito & Voucher \\
\hline Tilesia baccata (L.f.) Pruski & Sub & V.O 115 \\
\hline Verbesina macrophylla (Cass.) S.F. Blake & Arb & V.O 128 \\
\hline Wedelia hookeriana Gardner & Arb & V.O 153 \\
\hline \multicolumn{3}{|l|}{ Inuleae (1 gênero, 1 espécie) } \\
\hline Pluchea sagittalis (Lam.) Cabrera & Sub & D.D 423 \\
\hline \multicolumn{3}{|l|}{ Millerieae (2 gêneros, 2 espécies) } \\
\hline Acanthospermum hispidum DC. & Herb & V.O 114 \\
\hline Tridax procumbens $\mathrm{L}$. & Herb & V.O 162 \\
\hline \multicolumn{3}{|l|}{ Nassauvieae (1 gênero, 1 espécie) } \\
\hline Trixis antimenorrhoea (Schrank) Kuntze subsp. antimenorrhoea & Arb & V.O 121 \\
\hline \multicolumn{3}{|l|}{ Neurolaeneae (1 gênero, 1 espécie) } \\
\hline Enydra radicans (Willd.) Lack & Herb & V.O 129 \\
\hline \multicolumn{3}{|l|}{ Senecioneae ( 2 gêneros, 3 espécies) } \\
\hline Emilia fosbergii Nicolson & Herb & V.O 118 \\
\hline Emilia sonchifolia (L.) DC. ex Wight & Herb & V.O 116 \\
\hline Erechtites missionum Malme & Herb & D.D 140 \\
\hline \multicolumn{3}{|l|}{ Tageteae ( 3 gêneros, 5 espécies) } \\
\hline Pectis brevipedunculata (Gardner) Sch. Bip. & Herb & V.O 319 \\
\hline Pectis linifolia L. var. linifolia & Herb & V.O 320 \\
\hline Pectis oligocephala var. affinis (Gardner) Baker & Herb & H.P 463 \\
\hline Porophyllum ruderale (Jacq.) Cass. subsp. ruderale & Herb & V.O 291 \\
\hline Tagetes minuta $\mathrm{L}$. & Sub & V.O 196 \\
\hline \multicolumn{3}{|l|}{ Vernonieae ( 8 gêneros, 11 espécies) } \\
\hline Blanchetia heterotricha DC. & Arb & A.S 1832 \\
\hline Chresta martii (DC.) H. Rob. & Herb & V.O 224 \\
\hline Centratherum punctatum Cass. & Herb & V.O 119 \\
\hline Cyanthillium cinereum (L.) H. Rob. & Herb & D.C 131 \\
\hline Eremanthus capitatus (Spreng.) MacLeish & Arb & V.S 78 \\
\hline Lepidaploa chalybaea (Mart. ex DC.) H. Rob. & Sub & V.O 137 \\
\hline Lepidaploa cotoneaster (Willd. ex Spreng.) H. Rob. & Sub & V.O 122 \\
\hline Lepidaploa remotiflora (Rich.) H. Rob. & Herb & R.M 8051 \\
\hline Mattfeldanthus andrade-limae (G.M. Barroso) Dematt. & Arb & V.O 169 \\
\hline Stilpnopappus pratensis Mart. ex DC. & Sub & E.B 630 \\
\hline Stilpnopappus trichospiroides Mart. ex DC. & Sub & F.H 421 \\
\hline
\end{tabular}

Rob., Lepidaploa chalybaea (Mart. ex DC.) H. Rob. e Moquiniastrum oligocephalum (Gardner) G. Sancho. Este fato revela principalmente a dificuldade de coleta na caatinga devido a efemeridade da maioria das espécies herbáceas, bem como, a necessidade de levantamentos florísticos com foco em famílias que compõe grande parte do estrato herbáceo, permitindo assim uma melhor compreensão sobre a caracterização e delimitação biogeográfica da caatinga. 


\section{Chave para as espécies de Asteraceae da Ecorregião Raso da Catarina, Bahia}

1. Capítulos discoides (contêm flores com o mesmo tipo de corola e arranjo sexual).

2. Planta com látex; capítulos com todas as flores liguladas .....

Sonchus oleraceus

2'. Planta sem látex; capítulos com flores tubulosas, filiformes ou bilabiadas.

3. Brácteas involucrais em 1 série, conadas.

4. Folhas e brácteas involucrais com glândulas translúcidas paralelas; corola amareloesverdeada; cipsela fusiforme Porophyllum ruderale subsp. ruderale

4'. Folhas e brácteas involucrais sem glândulas translúcidas paralelas; corola vermelha ou lilás; cipsela cilíndrica.

5. Invólucro $0,5-0,7 \times 0,5-0,6 \mathrm{~cm}$; flores $50-56$; corola vermelha Emilia fosbergii

5'. Invólucro 1-1,2 × 0,1-0,15 cm; flores 35-40; corola lilás ........Emilia sonchifolia

3'. Brácteas involucrais em 2 séries ou mais, livres.

6. Planta dioica (indivíduo que produz capítulos com todas as flores apenas pistiladas ou estaminadas) ou ginodioica (indivíduo que produz capítulos com todas as flores bissexuais ou pistiladas).

7. Arbusto; lâmina foliar elíptica; capitulescência axilar

Moquiniastrum oligocephalum

7'. Erva a subarbusto; lâmina foliar linear a lanceolada; capitulescência terminal.

8. Lâmina foliar com margem inteira; receptáculo paleáceo; flores estaminadas $20-25$

Baccharis cinerea

8'. Lâmina foliar com margem serreada; receptáculo epaleáceo; flores estaminadas $50-53$ Baccharis glutinosa

6'. Planta monoica (indivíduo que produz capítulos com todas as flores bissexuais ou bissexuais e neutras ou bissexuais e pistiladas).

9. Corola amarela, bilabiada; ramos do estilete truncados, penicelados

Trixis antimenorrhoea subsp. antimenorrhoea

9'. Corola lilás a púrpura, alva a lavanda, creme, tubulosa; ramos do estilete agudos ou obtusos, papilosos ou pilosos.

10. Invólucro imbricado (brácteas sobrepostas em muitas séries de tamanhos gradualmente maiores podendo ser ou não decíduas na maturidade).

11. Pápus paleáceo e cerdoso-barbelado.

12. Ramos procumbentes, denso-pilosos; lâmina foliar com ápice agudomucronado, margem levemente serreada a denteada

Stilpnopappus trichospiroides

12'. Ramos eretos, cinéreo-pubescentes; lâmina foliar com ápice agudo, margem levemente sinuosa. Stilpnopappus pratensis

11. Pápus epaleáceo e cerdoso.

13. Capitulescência escorpioide ou cíncino.

14. Folhas pecioladas $2-3 \mathrm{~mm}$ compr.; flores periféricas zigomorfas, com tubo de 8-10 $\mathrm{mm}$ compr.

Mattfeldanthus andrade-limae

14'. Folhas sésseis a curto pecioladas até $1 \mathrm{~mm}$ compr.; todas as flores actinomorfas, com tubo de 1-4 mm compr.

15. Ramos angulosos, lanuginosos; folhas com face abaxial albo-tomentosa; flores 20-25.... Lepidaploa cotoneaster

15'. Ramos cilíndricos, estrigosos ou velutinos; folhas com face abaxial velutina ou tomentosa; flores 8-12.

16. Brácteas involucrais com tricomas glandulares sésseis, ápice agudo; cipsela ca. $1 \mathrm{~mm}$ compr.

Lepidaploa chalybaea 
16’. Brácteas involucrais sem tricomas glandulares, ápice acuminado; cipsela $2 \mathrm{~mm}$ compr. Lepidaploa remotiflora

13'. Capitulescência glomeruliforme, corimbiforme ou umbeliforme.

17. Arbusto a árvore.

18. Folhas com tricomas estrelados; invólucro campanulado a globoso; receptáculo fimbriado Blanchetia heterotricha

18'. Folhas com tricomas tectores simples; invólucro cilíndrico; receptáculo alveolado

17'. Erva.

Eremanthus capitatus

19. Folhas sésseis; capítulos solitários; flores 130

Centratherum punctatum

19'. Folhas pecioladas; capitulescência umbeliforme ou glomeruliforme; flores 10-20.

20. Folhas elípticas a oblongas; brácteas involucrais 2-3 séries.....

Cyanthillium cinereum

20'. Folhas ovadas a romboides; brácteas involucrais 5-6 séries

Chresta martii

10'. Invólucro subimbricado (brácteas mais longas ao longo das séries sobrepostas e pelo menos as mais externas não são decíduas) ou eximbricado (brácteas de comprimento subiguais e a maioria das mais internas são decíduas).

21. Planta volúvel; capítulos com 4 flores e 4 brácteas involucrais.

22. Ramos cilíndricos, não fistulosos; lâmina foliar ovada a obovada, com ápice arredondado a agudo, base cuneada; brácteas involucrais com ápice obtuso . Mikania obovata

22'. Ramos hexagonais, fistulosos; lâmina foliar cordada a deltoide, com ápice acuminado, base cordada a hastada; brácteas involucrais com ápice agudo ........ Mikania cordifolia

21'. Planta ereta; capítulos com número maior do que 4 flores e 4 brácteas involucrais.

23. Pápus plumoso; lacínias da corola densamente pubescentes e sem papilas.

24. Lâmina foliar lanceolada a triangular, base truncada; pecíolo $1,5-2 \mathrm{~cm}$ compr..... Trichogonia salviifolia

24'. Lâmina foliar elíptica, base atenuada; pecíolo até $1 \mathrm{~cm}$ compr.

25. Flores 30-35; lâmina foliar cartácea, com margem crenada a serreada. Trichogonia campestris

25’. Flores 20; lâmina foliar membranácea, com margem profundamente serreada Trichogonia heringeri

23'. Pápus cerdoso-barbelado, cerdoso-escabroso ou paleáceo-aristado; lacínias da corola setosas e papilosas.

26. Capítulos com até 30 flores.

27. Folhas alternas; brácteas involucrais 3-séries; receptáculo cônico

Conocliniopsis prasiifolia

27'. Folhas opostas; brácteas involucrais 2-séries; receptáculo plano

Koanophyllon conglobatum

26'. Capítulos com mais de 80 flores.

28. Lâmina foliar ovada; corola alva a lavanda; pápus paleáceo-aristado Ageratum conyzoides subsp. conyzoides

28'. Lâmina foliar lanceolada a estreitamente ovada; corola lilás; pápus cerdosobarbelado.... Platypodanthera melissifolia subsp. melissifolia

1'. Capítulos disciformes (contêm pelo menos dois tipos de flores tubulosas do disco com arranjos sexuais diferentes) ou radiados (contêm flores marginais zigomorfas, distintas das flores do disco).

29. Folhas alternas.

30. Ramos glabros; invólucro unisseriado; brácteas involucrais em 1 série.

Erechtites missionum

30'. Ramos com indumento; invólucro multisseriado (imbricado a subimbricado); brácteas involucrais em 2 ou mais séries.

31. Face abaxial da lâmina foliar albo-lanosa a puberulenta; anteras caudadas. 
32. Ramos com alas; lâmina foliar com a face abaxial puberulenta; brácteas involucrais cartáceas Pluchea sagittalis

32'. Ramos sem alas; lâmina foliar com a face abaxial albo-lanosa; brácteas involucrais papiráceas.

33. Capítulos com flores marginais até 5; pápus com cerdas livres na base.

Achyrocline satureioides

33'. Capítulos com flores marginais 40; pápus com cerdas concrescidas na base.....

Gamochaeta americana

31'. Face abaxial da lâmina foliar estrigosa, híspida ou pilosa; anteras ecaudadas.

34. Capitulescência paniculiforme; capítulos disciformes.

Conyza bonariensis

34'. Capítulos solitários ou em capitulescência corimbiforme; capítulos radiados.

35. Erva; flores do disco com corola amarela; pápus coroniforme-glanduloso

Egletes viscosa

35'. Subarbusto; flores do disco com corola alva; pápus aristado..... Verbesina macrophylla

29'. Folhas todas ou apenas inferiores opostas.

36. Folhas com glândulas; brácteas involucrais em 1 série, com glândulas.

37. Capitulescência corimbiforme; lâmina foliar com margem pinatissecta ........ Tagetes minuta

37'. Capítulos solitários; lâmina foliar com margem inteira.

38. Ramos hexagonais; margem da lâmina foliar revoluta; flores do disco 3; pápus aristado

Pectis linifolia var. linifolia

38'. Ramos cilíndricos; margem da lâmina foliar plana; flores do disco 10-16; pápus cerdoso.

39. Ramos pubescentes; capítulos sésseis a subsésseis $0,1 \mathrm{~cm}$ compr.; pápus homomorfo.

Pectis brevipedunculata

39'. Ramos pilosos; capítulos pedunculados 0,5-3 cm compr.; pápus heteromorfo.......

Pectis oligocephala var. affinis

36'. Folhas sem glândulas; brácteas involucrais em 2 séries ou mais, sem glândulas.

40. Capítulos com flores do raio neutras (flores sem androceu e gineceu).

41. Lâmina foliar com margem pinatissecta-serreada; pápus aristado com cerdas retrorsas

Bidens pilosa

41'. Lâmina foliar com margem de outros tipos; pápus ausente ou coroniforme-aristado.

42. Ramos prostrados; folhas sésseis; cipsela compressa; pápus coroniforme.

43. Lâmina foliar elíptica a ovada; brácteas involucrais externas com ápice agudo

Aspilia bonplandiana

43'. Lâmina foliar linear-lanceolada a oblonga; brácteas involucrais externas com ápice caudado

Aspilia martii

42'. Ramos eretos ou escandentes; folhas pecioladas; cipsela túrgida; pápus ausente ou cerdoso.

44. Páleas do receptáculo ovadas com ápice agudo; flores do raio 8; corola com limbo $6 \mathrm{~mm}$ compr. Tilesia baccata var. baccata

44'. Páleas do receptáculo obovadas com ápice acuminado; flores do raio 10; corola com limbo $11 \mathrm{~mm}$ compr.. Melanthera latifolia

40’. Capítulos com flores do raio pistiladas.

45. Flores com corola alva.

46. Ramos pubescentes a glabrescentes; capítulos sésseis; invólucro globoso.

Enydra radicans

46'. Ramos estrigosos; capítulos pedunculados; invólucro cilíndrico ou campanulado.

47. Páleas lineares; cipsela rugosa; pápus das cipselas das flores do disco inconspícuo. Eclipta prostrata

47'. Páleas obovadas; cipsela estriada; pápus das cipselas das flores do disco $3 \mathrm{~mm}$ compr. Blainvillea acmella

45'. Flores com corola amarela.

48. Pápus ausente, 2-cerdas ou ciliado.

49. Ramos glabrescentes; receptáculo cônico. Acmella uliginosa 
49'. Ramos estrigosos ou híspidos; receptáculo plano ou convexo.

50. Flor do raio 1; invólucro plano; brácteas involucrais estrigosas....

Delilia biflora

50'. Flores do raio 8; invólucro campanulado; brácteas involucrais uncinadas.... Acanthospermum hispidum

48'. Pápus plumoso ou coroniforme-ciliado.

51. Erva; flores do raio com corola $3 \mathrm{~mm}$ compr.; pápus plumoso Tridax procumbens

51'. Arbusto; flores do raio com corola 22-24 mm compr.; pápus coroniforme-ciliado Wedelia hookeriana

\section{Agradecimentos}

À CAPES, a concessão da bolsa de Mestrado à primeira autora. Aos curadores e técnicos dos herbários visitados ALCB, BAH, CEPEC, HRB, HUEFS e HUNEB.

\section{Referências}

Almeida, A.M.; Fonseca, C.R.; Prado, P.I.; AlmeidaNeto, M.; Diniz, S.; Kubota, U.; Braun, M.R.; Raimundo, R.L.G.; Anjos, L.A.; Mendonça, T.G.; Futada, S.M. \& Lewinsohn. T.M. 2005. Diversidade e ocorrência de Asteraceae em cerrados de São Paulo. Biota Neotropica 5: 1-17.

Anderberg, A.A.; Baldwin, B.G.; Bayer, R.G., Breitwieser, J.; Jeffrey, C.; Dillon, M.O.; Eldenas, P.; Funk, V.; Garcia-Jacas; N.; Hind, D.J.N.; Karis, P.O.; Lack, H.W.; Nesom, G.; Nordenstam, B.; Oberprieler, Ch.; Panero, J.L.; Puttock, C.; Robinson, H.; Stuessy, T.F.; Susanna, A.; Urtubey, E.; Vogt, R.; Ward, J. \& Watson, L.E. 2007. Compositae. In: Kubitzki, K. (ed.). The families and genera of vascular plants. Vol. 8. Springer, Heidelberg. Pp. 61-619.

Agra, M.F. \& Barbosa, M.R.V. 1996. Lista anotada das Asteraceae no estado da Paraíba. Revista Nordestina de Biologia 11: 73-86.

Baker, J.G. 1873. Compositae I: Vernoniaceae. In: Martius, C.F.P. \& Eichler, A.G. Flora Brasiliensis. F. Fleischer, Lipsiae. Vol. 6, part. 2, pp. 1-179.

Baker, J.G. 1876. Compositae II: Eupatoriaceae. In: Martius, C.F.P. \& Eichler, A.G. (eds.). Flora Brasiliensis. F. Fleischer, Lipsiae. Vol. 6, part. 2, pp. 181-374.

Baker, J.G. 1882. Compositae III: Asteroideae, Inuloideae. In: Martius, C.F.P. \& Eichler, A.G. (eds.). Flora Brasiliensis. F. Fleischer, Lipsiae. Vol. 6, part. 3, pp. 1-134.

Baker, J.G. 1884. Compositae IV: HeliantheoideaeMutisiaceae. In: Martius, C.F.P. \& Eichler, A.G. Flora Brasiliensis. F. Fleischer, Lipsiae. Vol. 6, part. 3, pp. 138-398.

Barroso, G.M.; Peixoto, A.L.; Ichaso, C.L.F.; Costa, C.G.; Guimarães, E.F. \& Lima, H.C. 1991. Sistemática das angiospermas do Brasil. Vol. 3. Universidade Federal de Viçosa, Viçosa. 326p.

Barbosa, M.R.V.; Agra, M.F.; Sampaio, E.V.S.B.; Cunha, J.P. \& Andrade, L.A. 2000. Diversidade florística na
Mata do Pau-Ferro. In: Porto, K.C.; Cabral, J.J.P. \& Tabarelli, M. Brejos de Altitude em Pernambuco e Paraíba: História Natural, Ecologia e Conservação. Ministério do Meio Ambiente, Brasília. Pp. 111-122.

Bautista, H.P. 1987. Pectis L. (Compositae-Tagetaea): espécies ocorrentes no Brasil. Rodriguésia 28: 5-107.

Beretta, M.E.; Fernandes, A.C.; Schneider, A.A. \& Ritter, M.R. 2008. A família Asteraceae no Parque Estadual de Itapuã, Viamão, Rio Grande do Sul, Brasil. Revista Brasileira de Biociências 6: 189-216.

BFG. 2015. Growing knowledge: an overview of Seed Plant diversity in Brazil. Rodriguésia 66: 10851113.

Filgueiras, T.S.; Brochado, A.L.; Nogueira, P.E. \& Gualla, G.F. 1994. Caminhamento: um método expedito para levantamentos florísticos qualitativos. Caderno de Geografia 12: 39-43.

Funk, V.A.; Susanna, A.; Stussey, T.F. \& Bayer, R.J. 2009. Systematics, evolution and biogeography of Compositae. IAPT, Vienna. 965p.

Giulietti, A.M.; Harley, R.M.; Queiroz, L.P.; Barbosa, M.R.V.; Bocage-neta, A.L. \& Figueiredo, M.A. 2002. Vegetação e flora da Caatinga. In: Sampaio, E.V.B.; Giulietti, A.M.; Virgínio, J. \& Gamarra-rojas, C. Espécies endêmicas da caatinga. Associação Plantas do Nordeste, Recife. Pp. 103-118.

Hind, D.J.N. 1995. Compositae. In: Stannard, B.L. Flora of the Pico das Almas, Chapada Diamantina, Bahia, Brazil. Royal Botanic Gardens, Kew. Pp. 175-278.

King, R.M. \& Robinson, H. 1987. The genera of the Eupatorieae (Asteraceae). Monographs in Systematic Botany from the Missouri Botanical Garden. Vol. 22. Missouri Botanical Garden, St. Louis. 581p.

Lemos, J.R. \& Meguro, M. 2010. Florística e fitogeografia da vegetação decidual da estação ecológica de Aiuaba, Ceará, Nordeste do Brasil. Revista Brasileira de Biociências 8: 34-43.

Mori, S.A.; Silva, L.A.M.; Lisboa, G. \& Coradin, L. 1989. Manual de manejo do herbário fanerogâmico. Centro de Pesquisa do Cacau, Ilhéus. 104p.

Nakajima, J.N. \& Semir, J. 2001. Asteraceae do Parque Nacional da Serra da Canastra, Minas Gerais, Brasil. Revista Brasileira de Botânica 24: 471-478.

Pereira, R.C.A. \& Melo, M.R.C.S. 2009. Checklist da Flora de Mirandiba: Asteraceae. In: Alves, M.; 
Araújo, M.F.; Maciel, J.R.; \& Martins, S. Flora da Mirandiba. Associação Plantas do Nordeste, Recife. Pp. 71-83.

Queiroz, L.P.; Conceição, A.A. \& Giulietti, A.M. 2006. Nordeste semi-árido: caracterização geral e lista das fanerógamas. In: Giulietti, A.M. \& Queiroz, L.P. Diversidade e caracterização das fenerógamas do semi-árido brasileiro. Vol. 1. Associação Plantas do Nordeste, Recife. Pp. 57-68.

Ritter, M.R. \& Baptista, L.R.M. 2005. Levantamento florístico da família Asteraceae na "Casa de Pedra" e áreas adjacentes, Bagé, Rio Grande do Sul. Iheringia: Série Botânica 60: 5-10.

Rodal, M.J.N.; Andrade, K.V.S.A.; Sales, M.F. \& Gomes, A.P.S. 1998. Fitossociologia do componente lenhoso de um refúgio vegetacional no município de Buíque, Pernambuco. Revista Brasileira de Biologia 58: 517-526.

Roque, N.; Bautista, H.P. \& Mota, A.C. 2012. Taxonomic revision of Trichogonia (Eupatorieae, Asteraceae): a South American Genus. Systematic Botany 37: 525-553.
Sampaio, E.V.S.B.; Giulietti, A.M.; Virginio, J. \& Gamarra-rojas, C.F.L. 2002. Vegetação e Flora da Caatinga. Associação Plantas do Nordeste, Recife. $176 \mathrm{p}$.

Santos, J.U.M. 2001. O gênero Aspilia Thou. (AsteraceaeHeliantheae) no Brasil. Museu Paraense Emílio Goeldi, Belém. 301p.

Siqueira-Filho, J.A. 2012. A flora das Caatingas do Rio São Francisco: História Natural e Conservação. Andrea Jakobsson Estúdio Editorial, Rio de Janeiro. 552p.

Thiers, B. [continuously updated]. Index Herbariorum: a global directory of public herbaria and associated staff. New York Botanical Garden's Virtual Herbarium. Disponível em $<$ http://sweetgum.nybg. org/ih/>. Acesso em 22 abril 2015.

Velloso, A.L.; Sampaio, E.V.S.B. \& Pareyn, F.G.C. 2002. Ecorregiões propostas para o bioma caatinga: resultados do seminário de planejamento ecorregional da Caatinga / Aldeia - PE 28 a 30 de novembro de 2001. Associação Plantas do Nordeste, Instituto de Conservação Ambiental - The Nature Conservancy do Brasil, Recife. 76p. 